\title{
Early intervention for children with autism: Parental priorities
}

\section{Sylvia Rodger}

\section{Michelle Braithwaite}

Deb Keen

University of Queensland

This paper describes a process of assisting parents of young children with Autistic Spectrum Disorder (ASD) to identify and prioritise their goals for their children's early intervention. A modified version of the Canadian Occupational Performance Measure (M-COPM) was used to facilitate this process. Twenty-two child-parent dyads involved in a home-based early intervention program participated in this study. Parents were able to identify and prioritise three to six early intervention goals for their children. Consistent with the core impairments of $A S D$, identified goals related to the domains of communication, behaviour, play and social interaction. The M-COPM was found to be a useful tool for enabling parents to identify goals for their children, when used and understood from a strong client and family-centred philosophical perspective. Pre- and postintervention parent ratings of goal performance and satisfaction are presented to demonstrate the use of the M-COPM as an outcome measure. Implications for practitioners in early childhood and special education settings, and areas for further research, are also discussed.

\section{Introduction}

It has been recognised for some time that early intervention for children with disabilities should not only focus on child outcomes but must also recognise the integral role families play in the development of their child (Bailey et al., 1998). Services that support families have frequently been discussed in terms of their family-centredness, and research has focused on identifying critical dimensions of family-centred practice (Allen \& Petr, 1996; Bailey et al., 1998; Begun, 1996; Dunst, Trivette \& Deal, 1994; Keen \& Knox, 2004; Knox et al., 2000; Murray, 2000; Turnbull \& Turnbull, 2001). Fundamental to a family-centred approach is 
the importance of matching early intervention support with the unique characteristics of each child and family (Bailey et al., 1990). As stated by Dunst et al. (1994), 'the greatest impact on child, parent, and family functioning is most likely to occur when interventions are based upon the needs, aspirations, and desires a family considers important' (p. 9).

Bailey et al. (1990) referred to the matching of intervention support to family ecology as 'goodness-of-fit'. The concept was adapted and applied to the development and implementation of behaviour support plans by Albin et al. (1996), who referred to this matching process as 'contextual fit'.

Some authors have argued that behaviour support plans that may be technically sound but lack good 'contextual fit' could be rejected by families, implemented inaccurately, or not sustained over time (Lucyshyn et al., 2002). Some research has suggested that enhancing 'contextual fit' by embedding strategies within family routines can lead to improved intervention outcomes. Moes and Frea (2000), for example, found that behavioural interventions, when developed in collaboration with families, lead to more favourable results. They compared two intervention approaches for children. In the contextualised intervention, an intervention was developed based on family routines and professional collaboration to guide implementation. The prescriptive intervention was based on a treatment package that parents were trained to implement. Contextualised intervention led to greater reductions in challenging behaviour and increases in on-task behaviour.

Another process thought to contribute to good 'contextual fit' is the identification of parental priorities and preferences in relation to intervention goals. Given that a good 'contextual fit' is said to be achieved when behaviour support plans reflect family goals and values (Lucyshyn et al., 2002), assessment of parental priorities and preferences would seem central to any intervention planning with families. Parental participation in educational goal-setting for students with disabilities through development of individual education plans (IEPs) is now a widelyadopted intervention strategy. The involvement of parents in IEPs and the 
commitment of services to the IEP process varies widely within and between countries. In Australia and New Zealand, administrative requirements may direct teachers to prepare IEPs; however, teachers are not legally compelled to do so (Ashman \& Elkins, 2002).

The importance of understanding and incorporating parental priorities within early intervention services is well-recognised (Sperry et al., 1999). However, few early intervention programs described in the literature have demonstrated how their programs have been derived from parental priorities for children with Autistic Spectrum Disorder (ASD). More frequently, parental input is sought and accommodated into structured programs where professionals have determined program content and goals (Dempsey \& Carruthers, 1997; lovanne et al., 2003). Identifying and incorporating intervention goals across home and early childhood settings is essential, however, if children with ASD are to gain the most from their early intervention experiences. Children with ASD frequently have difficulty generalising skills learned in one setting to another setting or context (Drasgow, Halle \& Phillips, 2001). Early childhood educators are in an ideal position to participate in the process of goal identification and prioritisation with families and, through this process, to use the concept of 'contextual fit' to address selected goals within their early childhood settings. In this way, goals may be shared across settings, but implementation of the goals can be tailored to the routines and opportunities within each setting.

The Canadian Occupational Performance Measure (COPM) (Law et al., 1998) is used to identify priorities for therapy and to document the client's self-rating of occupational performance and satisfaction. It is embedded in an understanding of client- and family-centred practice (Hannah \& Rodger, 2002; Law, Baptiste \& Mills, 1995) and the Canadian Model of Occupational Performance, which highlights the importance of the transaction between the client, occupation, and the environment (Law et al., 1990).

Law et al. (1998) and Pollock (1993) reported good utility of the COPM across a wide range of occupational performance dysfunctions (e.g. orthopaedics, pain, 
traumatic brain injury). The scoring of the COPM has been found to be responsive to changes in perceived occupational performance over time (Bodiam, 1999; Law et al., 1994; Wressle, Samuelsson \& Henriksson, 1999). When used as an outcome measure, pre- and post-performance and satisfaction ratings and change scores can be determined. A change score of two to three points is considered indicative of clinically significant change (Law et al., 1998). To date, there has been some use of the COPM with children (aged over seven years) (Miller et al., 2001; Polatajko et al., 2001). However, limited use with families has been reported in the literature.

The current study describes a process by which professionals involved in an early intervention program for children with ASD worked in partnership with parents to identify parental priorities and establish intervention goals. A modified version of the COPM (Rodger, Keen \& Braithwaite, 2003) was used with parents to facilitate the identification of priorities and goals for intervention. The study aimed to:

1. consider the utility of the Modified COPM (M-COPM) in assisting parents to identify and prioritise their goals; and

2. demonstrate the utility of the M-COPM as a self-report outcome measure, pre- and post-intervention.

\section{Method}

\section{Participants}

The participants were 22 child-parent dyads involved in an early intervention program for children with ASD, conducted through the University of Queensland during 2003. Families were referred to the program by paediatricians, speechlanguage pathologists, occupational therapists and educators. Children were four years of age or younger. Eighteen had a formal diagnosis of autism or ASD as determined by a paediatrician. Four children had early signs of ASD according to parent responses to questions on the Modified Checklist for Autism in Toddlers 
(M-CHAT) (Robins et al., 2001). The six critical questions pertain to social relatedness, such as 'does your child take an interest in other children?'; and early communication skills, for example, 'does your child ever use his/her index finger to point, to indicate an interest in something?' (Robins et al., 2001, p. 142). The children ranged in age from 27 months (two years, three months) to 49 months (four years, one month). The mean chronological age of the children was 39 months (three years, three months). There were five female and 17 male children.

$10(27.8 \%)$ of the 23 parents involved in this study were engaged in home duties, while $8.3 \%(n=3)$ were in full-time study. The percentage of parents in the sample who had completed high school or a diploma was similar to that of the general population, while the percentage of parents who had completed undergraduate and postgraduate degrees was slightly higher (Australian Bureau of Statistics, 2002).

\section{Instruments}

\section{Modified Canadian Occupational Performance Measure (M-COPM)}

Two modifications were made to the COPM to create the M-COPM. First, when working with children (and their parents), it was important to reframe occupations as the things children need to do, want to do and are expected to do in their daily lives. For young children with compromised language and communication abilities, parents are in the best position to identify their child's occupational performance issues, prioritise these and, in collaboration with professionals, identify realistic intervention goals. Second, the occupational area 'Productivity/Work' was substituted with 'Communication/Behaviour', as children from two to four years do not engage in formal school activities. Issues of communication and behaviour are pervasive deficits experienced by children with ASD. Parents were asked to consider how their child's communication and behaviour difficulties impacted on the child's ability to engage in their daily occupations. They were asked to reflect on a typical day for their child and then 
guided to think about potential areas of difficulty experienced by the child, such as communication, behaviour, play, leisure, self-care, rest and relaxation. Specifically, parents reflected on their child's ability to have their needs met, express themselves, understand others' communication and interact with others, and to identify any concerning behaviour or issues with daily routines and transitions. Self-care (eating, toileting, bathing, grooming/hygiene) and play/leisure were retained. In discussing play, parents were asked to reflect on family socialisation, play at home and in early childhood settings, and play likes and dislikes.

\section{Procedure}

Parents participated in a family-centred early intervention program designed to provide information and to help parents achieve their goals for their child. It involved a two-day workshop for parents, followed by 10 home-visits, provided twice a week over five weeks by a home facilitator. The home facilitators were doctoral students, two in the field of educational psychology and the third in special education. All had experience working with families of young children with ASD and were provided with training in the assessments and techniques used in the program. The modified version of the Canadian Occupational Performance Measure (M-COPM) (Rodger et al., 2003) — which can be obtained from the corresponding author-was administered during the first visit following the twoday workshop. This visit was scheduled, where possible, at a time convenient to both parents. In the majority of cases, both parents were involved in the administration of the M-COPM. The second, post-intervention, administration occurred within two weeks of the completion of the home visits.

Administration of the M-COPM involved four steps:

1. Parents were asked to identify occupations that were difficult for their son/daughter in regard to self-care, play, rest and relaxation;

2. parents then rated these difficulties using a 10-point scale to identify priorities for intervention; 
3. parents then rated current performance and satisfaction of their son/daughter on three to five of the priority areas using a 10-point scale; and finally

4. parents rated performance and satisfaction post-intervention.

\section{Data analysis}

The goals identified for each child from the M-COPM were examined by two independent raters, and domains were identified. All 90 goals were then assigned to one of the following five domains: communication, social interaction, behaviour, play, and self-care. Communication referred to any goal pertaining to requesting, signing, gesturing, asking for help, or language and communication skills, while social interaction referred to any goal relating to the social reciprocity of communication (e.g. sharing, taking turns, conversation with another child or adult). Behaviour referred to any goal relating to decreasing socially unacceptable behaviour, such as tantrums, screaming, or replacing any such behaviour with a more socially acceptable behaviour. Play goals were defined as those pertaining to enhancing play skills on their own, with others, or in different settings. Self-care goals were any goals pertaining to eating, dressing, toileting, bathing or grooming. Rater training was undertaken with the classification system using hypothetical goals until 95 per cent agreement was reached. Inter-rater agreement was calculated using the formula: (number of agreements) divided by (number of agreements plus disagreements), multiplied by 100 . The domains of goals were recorded and expressed as percentages of the total number of goals $(\mathrm{N}=90)$. The mean pre- and post-intervention performance and satisfaction ratings for the M-COPM for each goal domain for all children were calculated.

\section{Results}

Inter-rater agreement for goal domain classification was 92.2 per cent. For specific domains, inter-rater agreement was 100 per cent for self-care, 97.3 per cent for communication, 94.7 per cent for behaviour, 91.7 per cent for play, and 69.2 per cent for social interaction. No goals were classified as 'Other'. 
Parents identified between three and six goals. The mean number of goals was 4.09. The domain of communication represented the highest priority area of goals identified by parents. Table 1 provides examples of goals in each of the domains.

\section{[Insert Table 1 about here]}

Figure 1 highlights the percentage of goals per domain for the entire cohort of children across all 90 goals. It is clear from this figure that the early intervention goals most frequently identified by parents of children with ASD between two and four years were in the domain of communication, followed by behaviour, social interaction, and play. Specifically, within the communication domain, requesting, enabling children to get their basic needs met and following basic instructions were frequently expressed goals. In terms of behaviour, minimising inappropriate and unusual behaviours, self-stimulation and tantrums were of paramount importance. In respect to social interaction, joining in, sharing and taking turns, and increasing eye contact were frequently raised. In terms of play, independently playing on their own, playing alongside and with others, and extending play repertoire were well-represented. Self-care priorities involved toileting, grooming and eating routines, for which sensory hypersensitivity or communication of needs often appeared to be underlying issues.

\section{[Insert Figure 1 about here]}

Figure 2 illustrates parents' ratings of pre- and post-intervention performance and satisfaction on the M-COPM goals. For all goal domains, post-performance and satisfaction scores were higher than pre-intervention scores. With the exception 
of play (where mean change scores were 1.4 and 1.5), mean change for the other four domains ranged from 2 to 3.2 points.

\section{[Insert Figure 2 about here]}

\section{Discussion}

First, this study has demonstrated that parents raising young children (aged two to four years) with ASD identified between three and six early intervention goals for their child, which were primarily in the domains of communication, behaviour, social interaction and play. Not surprisingly, these goals reflect the core impairments seen in ASD (Charman \& Baird, 2002; DSM-IV, APA, 1994). Specifically, parents' goals reflected their everyday interactions with their children, such as hair-brushing, establishing a toileting routine, responding to 'come here', requesting food and toys, and sharing and taking turns with siblings. In addition to describing their goals, the M-COPM enabled parents to prioritise these goals, using the rating scale format for importance.

Second, this study found that the M-COPM was clinically useful, enabling facilitators to help parents reflect upon their children's occupations and consider the difficulties they experience. The modifications that enabled this reflection appear to have been successful in assisting this process. Specifically, the structure of the M-COPM interview helped parents consider communication, behaviour, play, self-care, routines and transitions, as well as family socialisation. Important prerequisites in utilising the M-COPM include the establishment of rapport with parents prior to the interview, finding a mutually convenient time for interview, and ensuring that the interviewer embodies the underpinning philosophies of family-centred practice and has developed excellent listening and interviewing skills. In particular, the interviewer needs to acknowledge parents' expertise with their own children and place their own disciplinary knowledge and 
expertise in perspective, aiming all the time to understand the parents' perspectives. Without this, goals can be inappropriately framed in disciplinespecific jargon, such as 'to increase joint attention while looking at a picture book' or 'to decrease sensory hypersensitivity to enable nail cutting', rather than being grounded in the parents' language and experience. The use of discipline-specific jargon disempowers parents who may be unable to decipher professionals' language. If parents are to be 'true' partners with professionals in assisting their children's development, conscious effort on the part of professionals is required. Professionals need to be sensitive to language use and ensure that other practices involved in goal-setting are parent friendly (e.g. keeping goal-setting meetings small in size by minimising the number of professionals present, and holding meetings at mutually-convenient times and in a family-friendly location) (Dunst et al., 1994; Turnbull \& Turnbull, 2001). The M-COPM provides a clear yet flexible structure for both parental goal identification and prioritisation.

\section{Implications for early childhood professionals}

Parent-identified goals in the domains of communication, behaviour, play and social interaction frequently pervade all environmental contexts in which the child with ASD functions. Knowledge of these goals can assist early childhood educators in both special education and inclusive settings to discuss with parents how they envisage these goals being supported with specific interventions (Schwartz, Billingsley \& McBride, 1998). This enables a consistent approach across home, early childhood and community settings. Awareness of the parents' goals for a child in a childcare setting can also assist early childhood professionals to make the most of their time in this environment, which is frequently highly sought after and valued by parents. For example, requesting food and toys was an identified goal for some parents in this study (see Table 1). While setting differences must be considered by the early childhood professional, this goal may be addressed both at home and at school through the consistent use of the Picture Exchange Communication System (Bondy \& Frost, 1994) and offering frequent requesting opportunities. The involvement of family and 
professionals in all of the contexts in which the child engages is recognised as one of the key components of effective programs for young children with autism (Dawson \& Osterling, 1997). In addition, consistency of management assists with the generalisation of skills and development of new behaviours across multiple settings - a factor known to be critical for these children (Drasgow et al., 2001).

While goal-setting is not typically undertaken for all children in early childhood settings, it may be relevant to children with special needs. The M-COPM is a useful method for identifying parents' priorities in both inclusive and special educational settings. It also provides a structure for discussing parents' expectations of what they wish their child to achieve in inclusive settings (e.g. socialisation goals). This can assist educators to clarify expectations of how they will support the child in various settings to achieve priority goals, as well as to determine realistic expectations of each educational setting. The M-COPM could also be used for such discussions in transdisciplinary team settings, where one team member as primary case manager may undertake the M-COPM with parents to assist with goal identification, and report back to the team who can then identify the necessary expertise to develop appropriate interventions. Such practices work to empower parents as equal partners in their child's early education.

Both the identification of parental priorities and preferences (Lucyshyn et al., 2002) and the involvement of family routines have been found to support 'contextual fit' for behaviour support plans. Expanding on this concept of 'fit' allows us to hypothesise that 'contextual fit' could also involve embedding routines in educational settings (Schepis et al., 2001) and ensure that parental priorities and preferences are also understood in these environments.

\section{Limitations of the study}

This study is limited by the relatively small sample size of child-parent dyads who were accessing a primarily home-based early intervention program within the metropolitan area of Brisbane, Australia. These parents tended to be middle to 
upper-middle class, generally well-educated, and were married or in permanent relationships. On the whole, their level of education was higher than the general Australian population, and their occupations fell within the two highest occupational groupings on the Australian Standard Classification of Occupations (Najman \& Bampton, 1991). The parent sample was also relatively culturally homogeneous in terms of being Caucasian Australian ( $n=83 \%)$. Therefore, caution is necessary in generalising these findings to parents from other cultural or socio-economic groups and educational backgrounds, where disempowering experiences may be more common.

The other limitation was the only moderate inter-rater agreement for social interaction (69.2\%), compared to 90 per cent agreement for all other goals. Also, the domain proved difficult to classify precisely, and so inter-rater discrepancies related to decisions about whether the goal was primarily about communication or whether social interaction was more important. Finally, results were based on parent self-report, with lack of triangulation of goal achievement using measures other than the M-COPM.

\section{Conclusion}

It would seem that the tool provides a useful means for identifying and prioritising goals in home-based programs, early special education and regular early childhood settings. In addition, it provides a means of documenting outcomes of intervention by way of addressing parental perceptions of change, in both the child's performance in relation to specific goals as well as their satisfaction with that performance. Used within a framework of family-centred practice, the MCOPM appears to have potential in assisting parents to identify and prioritise early intervention goals for their children with ASD.

\section{References}

Albin, R., Lucyshyn, J., Horner, R., \& Flannery, K. (1996). Contextual fit for behavior support plans: A model for 'goodness of fit'. In L. Koegel, R. Koegel \& 
G. Dunlap (Eds), Positive behavioral support: including people with difficult behavior in the community (pp. 81-98). Baltimore: Paul H Brookes.

Allen, R., \& Petr, C. (1996). Toward developing standards and measurements for family-centered practice in family support programs. In G. H. S. Singer, L. E. Powers \& A. Olson (Eds), Redefining family support. Innovations in the publicprivate partnerships (pp. 57-85). Baltimore: Paul H Brookes.

American Psychiatric Association (1994). Diagnostic and Statistical Manual of Mental Disorders (DSM-IV) (4th edn). Washington DC: American Psychiatric Association.

Ashman, A., \& Elkins, J. (2002). Rights and learning opportunities. In A. Ashman \& J. Elkins (Eds), Educating children with diverse abilities (pp. 41-72). Frenchs Forest, NSW: Pearson Education Australia.

Australian Bureau of Statistics (2002). Education and work (no. 6227.0). Canberra: Commonwealth Government.

Bailey, D., McWilliam, R., Darkes, L., Hebbeler, K., Spiker, D., \& Wagner, M. (1998). Family outcomes in early intervention: a framework for program evaluation and efficacy research. Exceptional Children, 64, 313-328.

Bailey, D., Simeonsson, R., Winton, P., Huntington, G., Comfort, M., Isbell, P., O'Donnell, K., \& Helm, J. (1990). Family-focused intervention: A functional model for planning, implementing, and evaluating individualized family services in early intervention. Journal of the Division for Early Childhood, 10, 156-171.

Begun, A. L. (1996). Family systems and family-centred care. In P. Rosen, A. D. Whitehead, L. I. Tuchman, G. S. Gesien, A. L. Begun \& L. Irwin (Eds), Partnerships in family-centred care: a guide to collaborative early intervention (pp. 33-63). Baltimore: Paul H Brookes. 
Bodiam, C. (1999). The use of the Canadian Occupational Performance Measure for the assessment outcome on a neurorehabilitation unit. British Journal of Therapy and Rehabilitation, 62(3), 123-126.

Bondy, A., \& Frost, L. (1994). The picture exchange communication system. Focus on Autistic Behavior, 9, 1-19.

Charman, T., \& Baird, G. (2002). Practitioner review: Diagnosis of autism spectrum disorder in 2- and 3-year-old children. Journal of Child Psychology and Psychiatry, 43(3), 289-305.

Dawson, G., \& Osterling, J. (1997). Early intervention of autism: Effectiveness and common elements of current approaches. In M. Guralnick (Ed.), The effectiveness of early intervention: Second generation research (pp. 307-326). Baltimore: Paul H Brookes.

Dempsey, I., \& Carruthers, A. (1997). How family-centered are early intervention services? Staff and parent perceptions. Journal of Australian Research in Early Childhood Education, 1, 105-114.

Drasgow, E., Halle, J., \& Phillips, B. (2001). Effects of different social partners on the discriminated requesting of a young child with autism and severe language delays. Research in Developmental Disabilities, 22, 125-139.

Dunst, C. J., Trivette, C. M., Davis, M., \& Cornwell, J. (1994). Characteristics of effective help giving practices. In C. J. Dunst, C. M. Trivette \& A. G. Deal (Eds), Supporting and strengthening families, Volume 1: Methods, strategies and practices (pp. 171-186). Cambridge, MA: Brookline.

Dunst, C. J., Trivette, C. M., \& Deal, A. G. (1994). Enabling and empowering families. In C. J. Dunst, C. M. Trivette \& A. G. Deal (Eds), Supporting and strengthening families, Volume 1: Strategies and practices (pp. 2-11). Cambridge, MA: Brookline. 
Hanna, K., \& Rodger, S. (2002). Towards family-centred practice in paediatric occupational therapy: a review of the literature on parent-therapist collaboration. Australian Occupational Therapy Journal, 49, 14-24.

lovanne, R., Dunlap, G., Huber, H., \& Kincaid, D. (2003). Effective educational practices for students with autism spectrum disorders. Focus on Autism and Other Developmental Disabilities, 18, 150-165.

Keen, D., \& Knox, M. (2004). Approach to challenging behaviour: a family affair. Journal of Intellectual \& Developmental Disability, 29(1), 52-64.

Knox, M., Parmenter, T. R., Atkinson, N., \& Yazbeck, M. (2000). Family control The views of families who have a child with a disability. Journal of Applied Research in Intellectual Disability, 13, 17-28.

Law, M., Baptiste, S., Carswell, A., McColl, M., Polatajko, H., \& Pollock, N. (1998). Canadian Occupational Performance Measure Manual (3rd edn). Ottawa: CAOT.

Law, M., Baptiste, S., McColl, M., Opzoomer, A., Polatajko, H., \& Pollock, N. (1990). The Canadian Occupational Performance Measure: An outcome measure for occupational therapy. Canadian Journal of Occupational Therapy, 57(2), 82-87.

Law, M., Baptiste, S., \& Mills, J. (1995). Client-centred practice: What does it mean and does it make a difference? Canadian Journal of Occupational Therapy, 62, 250-257.

Lucyshyn, J., Kayser, A., Irvin, L., \& Blumberg, E. (2002). Functional assessment and positive behavior support at home with families. In J. Lucyshyn, G. Dunlap \& R. Albin (Eds), Families and positive behavior support (pp. 97-132). Baltimore: Paul H Brookes. 
Miller, L., Missiuna, C., Macnab, J., Malloy-Miller T., \& Polatajko, H. (2001).

Clinical description of children with Developmental Coordination Disorder. Canadian Journal of Occupational Therapy, 68, 5-15.

Moes, D., \& Frea, W. (2000). Using family context to inform intervention planning for the treatment of a child with autism. Journal of Positive Behavior Interventions, 2, 40-47.

Murray, P. (2000). Disabled children, parents and professionals: partnership on whose terms? Disability and Society, 15, 683-698.

Najman, J. M., \& Bampton, M. (1991). An ASCO based occupational status hierarchy for Australia: A research note. Australian and New Zealand Journal of Developmental Disabilities, 19, 45-52.

Polatajko, H., Mandich, A., Miller, L., \& Macnab, J. (2001). Cognitive Orientation to Daily Occupational Performance (CO-OP): Part II - the evidence. Physical \& Occupational Therapy in Pediatrics, 20, 83-106.

Pollock, N. (1993). Client-Centred Assessment. The American Journal of Occupational Therapy, 47(4), 298-300.

Robins, D. L., Fein, D., Barton, M. L., \& Green, J. A. (2001). The Modified Checklist for Autism in Toddlers: an initial study investigating the early detection of autism and pervasive developmental disorders. Journal of Autism and Developmental Disorders, 31, 131-144.

Rodger, S., Keen, D., \& Braithwaite, M. (2003). Modified Canadian Occupational Performance Measure (M-COPM). Brisbane: Unpublished manuscript.

Schepis, M. M., Ownbey, D. H., Ownbey, J., \& Parsons, M. B. (2001). Training support staff to embed teaching within natural routines of young children with disabilities in an inclusive preschool. Journal of Applied Behavior Analysis, 34, 313-327. 
Schwartz, I. S., Billingsley, F. F., \& McBride, B. M. (1998). Including children with autism in inclusive preschools: strategies that work. Young Exceptional Children, 2(1), 19-26.

Sperry, L., Whaley, K., Shaw, E., \& Brame, K. (1999). Services for young children with autism spectrum disorder: voices of parents and providers. Infants and Young Children, 11(4), 17-33.

Turnbull, A., \& Turnbull, H. R. (2001). Families, professionals, and exceptionality: Collaborating for empowerment (4th edn). New Jersey: Prentice-Hall.

Wressle, E., Samuelsson, K., \& Henriksson, C. (1999). Responsiveness of the Swedish version of the Canadian Occupational Performance Measure.

Scandinavian Journal of Occupational Therapy, 6, 84-89. 
Table 1. Examples of goals by domain for children in all cycles $(n=22$ children, $\mathrm{n}=90$ goals) during the M-COPM interview

\begin{tabular}{ll}
\hline Domain classification & $\begin{array}{l}\text { Examples of goals identified by parents } \\
\text { during M-COPM. }\end{array}$ \\
\hline Communication & To ask before going to the fridge \\
& To increase ability to make needs \\
& known \\
& To communicate need for toilet \\
& Requesting food and toys \\
& Responding to 'come here' \\
& To improve eye contact \\
To join in more with Mum and siblings & To share and take turns with sibling \\
To improve tolerance of others & engaging in play \\
To express frustration in appropriate & To reduce amount of time spent self- \\
stimulating & To reduce the frequency of unusual \\
behaviour & \\
Tehaviour & To react calmly when mess/spills made \\
&
\end{tabular}


To stay beside parents when walking in open spaces

Play

To play by him/herself for five minutes

To play with nominated friend for five minutes

To play calmly alongside sibling

To engage in functional play with a doll

To increase play skills with other children

Self-care

To tolerate hair-brushing (tolerate parting and bunches)

To sit on toilet for five minutes.

To tolerate sitting on toilet properly

To establish a regular toilet routine 


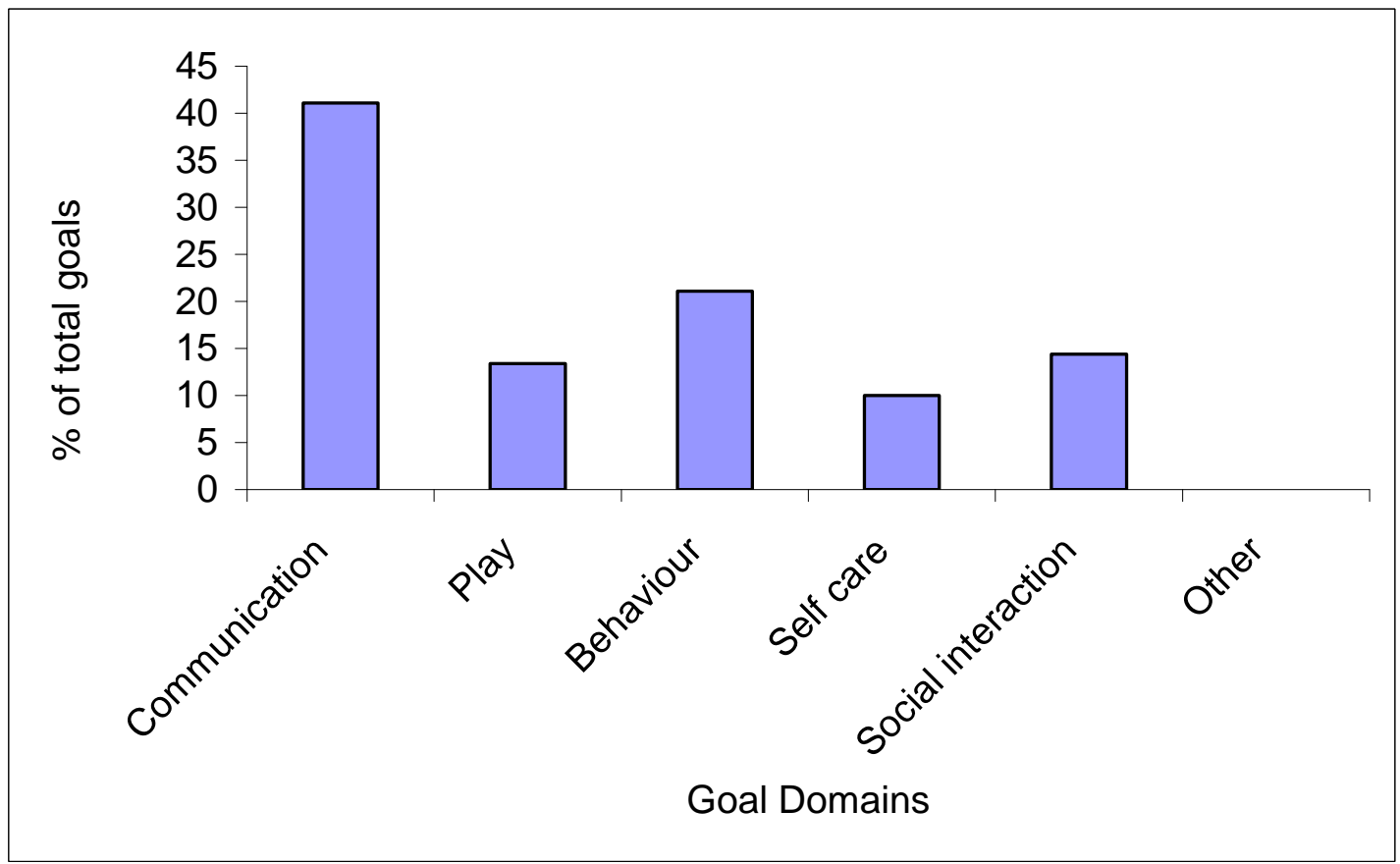

Figure 1. Percentage of total goals by domains ( $\mathrm{N}=90$ goals) for all children $(\mathrm{N}=22)$ 


\section{Pre-Post M-COPM Ratings for All Goals}

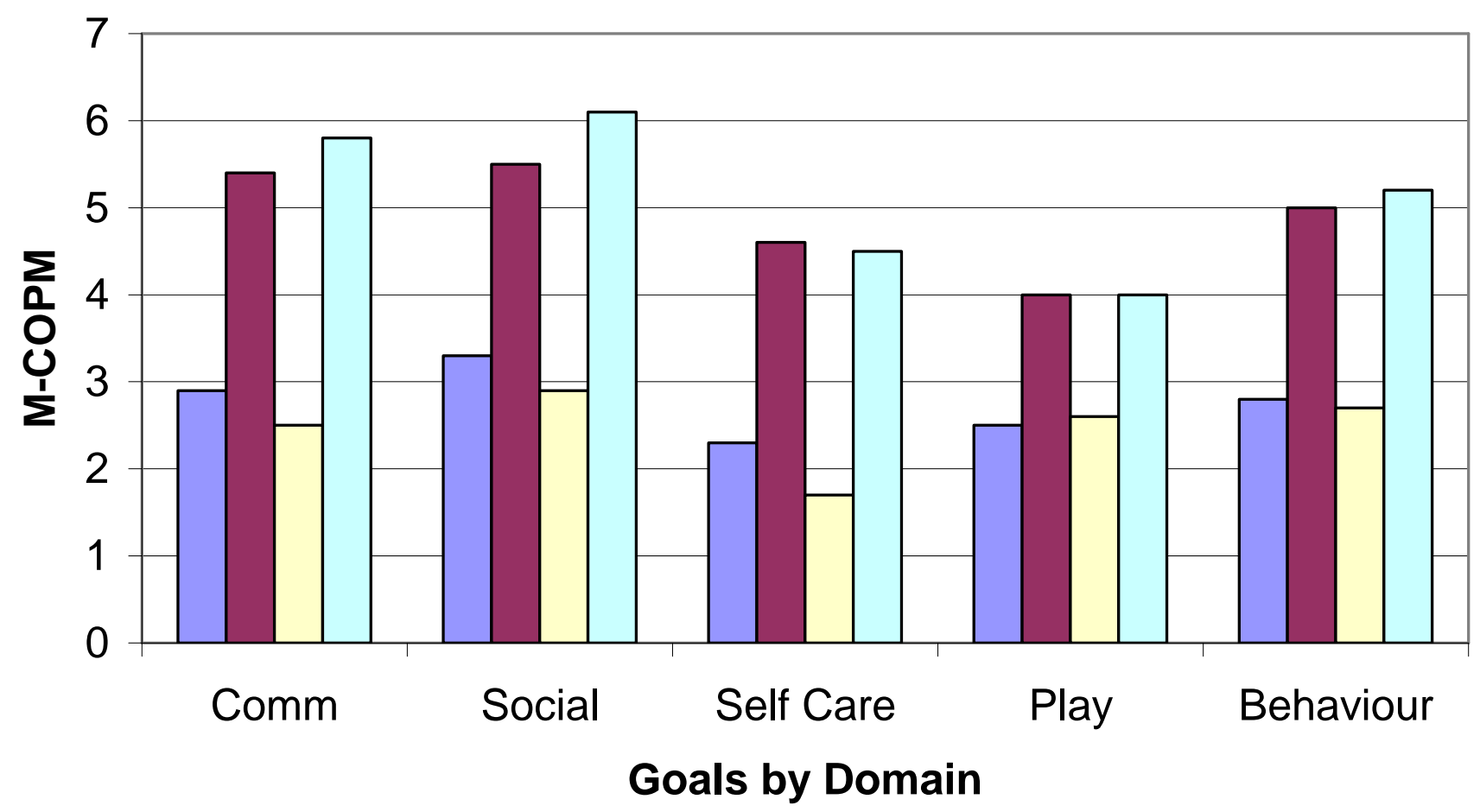

$\square$ Pre Performance $\quad \square$ Post Performance $\quad \square$ Pre Satisfaction $\quad \square$ Post Satisfaction

Figure 2. Pre- and post- intervention performance scores for all goals ( $\mathrm{N}=90)$ across all domains 